\title{
INVESTIGATIONS ON THE ACCUMULATION, TISSUE DISTRIBUTION AND TOXICITY OF SILVER NANOPARTICLES IN AMAMMALIAN MODEL
}

\section{Sameh Mohamed Abouzead', Abdelmordy M. Mohamed²,}

\section{Ahmed R. Ezzat ${ }^{3}$ and Gamal M. Morsy}

${ }^{1}$ Chief Manager of the Biology Department, Technical Research Centre, Cairo, Egypt E-mail: samehzead77@gmail.com

${ }^{2}$ Professor of Genetics and Molecular Biology, Zoology Department, Faculty of Science, Ain Shams University, Cairo, Egypt

${ }^{3}$ Professor of Physiology, Zoology Department, Faculty of Science, Ain Shams University, Cairo, Egypt

${ }^{4}$ Professor of Toxicology, Zoology Department, Faculty of Science, Cairo University, Giza, Egypt

Cite this article:

Sameh M.A., Abdelmordy M.M., Ahmed R.E., Gamal M.M. (2021), Investigations on the Accumulation, Tissue Distribution and Toxicity of Silver Nanoparticles in Amammalian Model. African Journal of Biology and Medical Research 4(4), 34-52. DOI: 10.52589/AJBMRCXKGWBOO.

\section{Manuscript History}

Received: 8 Nov 2021

Accepted: 29 Nov 2021

Published: 13 Dec 2021

Copyright $\odot 2020$ The Author(s). This is an Open Access article distributed under the terms of Creative Commons AttributionNonCommercial-NoDerivatives 4.0 International (CC BY-NC-ND 4.0), which permits anyone to share, use, reproduce and redistribute in any medium, provided the original author and source are credited.
ABSTRACT: The current work aimed to investigate the potential toxicity of Ag-NPs in male rabbits as a mammalian model, following acute and sub-acute dermal exposure terms. The rabbits were topically exposed to a single acute dose of $2.0 \% \mathrm{Ag}-\mathrm{NPs}$ and the assessments were conducted4 days latter, while a dose of $0.5 \%$ was administered every other day for the sub-acute exposure in two time periods ( 7 and 14 days). The accumulation and retention of Ag+ ions in the skin and their distribution in other vital tissues were measured. In addition, the concentrations of total proteins, lipidparameters and levels of different oxidative stress biomarkers in the skin were also evaluated. The results demonstrated the ability of Ag-NPs to penetrate the skin and accumulate rapidly in the dermal skin, then spread out to the blood and other vital organs. The spleen and liver seemed to be the main target organs. The high levels of $\mathrm{Ag}+$ tissue accumulation affected the concentration of total proteins and acted as a stressor stimulus within the skin, thereby, initiating oxidative stress. The liberated ROS caused disruption of the activities of the antioxidant enzymes GST, GSH, GR, GPX, SOD and CAT as well as increased levels of $\mathrm{H}_{2} \mathrm{O}_{2}$ and MDA. The current work showed that the toxicity of Ag-NPs could be attributed to the release of Ag+ions and the subsequent excessive generation of ROS.

KEYWORDS: Silver Nanoparticles, Bioaccumulation, Toxicity, Oxidative stress, Proteins. 


\section{INTRODUCTION}

Nanomaterials (NMs) are innovative substances that have structural components smaller than $100 \mathrm{~nm}$ in at least one dimension. They include nanoparticles (NPs), nanofibers, nanotubes and nano-composite materials (Sajid and Płotka, 2020). These nanomaterials might be naturally occurring such as viruses and volcanic ashes or engineered NPs which are intentionally manufactured for a specific function (Mulvaney, 2015). The significant importance of these NMs is mainly relying on their remarkable optical, electrical, catalytic, magnetic, thermal and mechanical transformations which generate novel properties completely different from theirequivalent bulky materials. These peculiar propertiesprovide them with a wide spectrum of applications in different fields (Baydaet al., 2019).

Today, NMs are essentially involved in hundreds of commercially available products and the number of applications for these particles is constantly growing. It is currently estimated that silver nanoparticles (Ag-NPs)-containing products acquired the highest degree of commercialization, among other metal NPs. They are involved in a wide group of products such as cosmetics, sunscreens, paints textiles and several medical and healthcare products (Beyeneet al., 2017). However, the significant increase in nanotechnology applications raised a great concern associated with many environmental, health and safety issues.

The questionable parts are mainly about how NMs may be released from the enabled products and their biological interactions with the human body and environmental system. This issue is still not fully understood and may result in multiple unpredictable effects and irreversible damage (Staronet al., 2020). Consequently, progressive efforts are growing in order to monitor the production and liberation of NMs as well as, enforcing defined cytotoxic and genotoxic limitations for minimizing their risk which may enablesafer nano-products (Larsson et al., 2019).

In this context, the exceptional properties of Ag-NPs that give them the advantage over others could also lead to a modified distribution model or different bio-kinetic behaviours, thereby producing unexpected biological interactions and toxic effects (Antony et al, 2015). On the other hand, the widespread use of antimicrobial textiles, wound dressings, military protection clothes, cosmetics and many other Ag-NPs containing products constantlyincreasethe human dermal exposure to these NPs (Sapkota et al., 2017).

Recentstudies have demonstrated the ability of Ag-NPs to induce toxic effects in a number of animal species and cultured cells. The toxic behaviours are often associated with the release of silver free ions, intercellular accumulation, generation of reactive oxygen species (ROS) and the induction of oxidative stress (Gopisettyet al., 2019; Čapek and Roušar, 2021). The effects reported in these studies could not be directly compared with each other because of the differences in cell types and species, as well as experimental conditions, and the assessed parameters. More importantly, the variation in the properties and specifications of Ag-NPs which represent one of the key players in such toxicity actions (Gherasimet al., 2020).

Accordingly, the present work was designed to investigate the potential toxicity of acute and sub-acute dermal exposure to Ag-NPs inrabbits as an animal model. Special attention was given to the accumulation and retention of $\mathrm{Ag}+$ ions in the skin, and theirspread and distribution in other vital tissues. To broaden the picture and the depth of this inclusive study, 
the antioxidant balance, total protein levels and the lipidprofileparameters in the skin were also evaluated in different experimentation terms.

\section{METHODOLOGY}

\section{Silver Nanoparticles Preparation and Characterization}

Spherical shape Ag-NPs with an average particle size of 10 to $15 \mathrm{~nm}$, and a purity of $99.9 \%$, were supplied by Skyspring Nanomaterials, Inc. (Houston, USA). The non-sonicated powder was prepared for experimentation as aqueous suspensions in water media. The concentrations were achieved by mixing w/v "percent weight per volume". Thus, $2.0 \%$ aqueous solution was made by dissolving $2.0 \mathrm{~g}$ of the powder in $100 \mathrm{ml}$ of de-ionized water, then it was diluted to the desired concentration. The aqueous suspension was then ultrasonicated using an ultrasonic device (Misonix4000) for 20 to 30 min to avoid agglomeration.

In order to characterize the shape, size, and aggregation of non-sonicated Ag-NPs powder, the scanning electron microscope (SEM) was used. The analysis was done by using MIRA3 (TESCAN, Czech Republic) software-controlled SEM integrated with Energy Diffraction Xray (EDX) system. A thin film of Ag-NPs was prepared on a carbon-coated copper grid by dropping a small amount of the sample on the grid. The samples were analyzed by the SEM using "In-Beam Detector" for high-resolution imaging, under low accelerating voltages ranging from 15 to $25 \mathrm{kV}$ with the maximum magnification. Image acquisition and processing were done using (Mira TC) software. The particles size analyses were done by manual choosing of particles with different positions in the images, and the size was automatically measured via the software. In addition, the elemental analysis was done automatically using the EDX unit through the "Easy EDX" software supplied with the "OXFORD" elements reference library.

The transmission electron microscopy (TEM) technique was applied for characterizing the ultrasonicated Ag-NPs suspension, with the aid of JEOL, JEM1400-plus TEM, with an acceleration voltage of $100 \mathrm{kV}$ and magnification range up to 48000x. Carbon coated 200 mesh copper grids were pre-treated with $20 \mu \mathrm{l}$ of poly-L-lysine $0.01 \%(\mathrm{w} / \mathrm{v})$ for $15 \mathrm{~min}$. Then, $3 \mu \mathrm{l}$ of Ag-NPs suspension were dropped into the grids for $5 \mathrm{~min}$ and rinsed with $3 \mu \mathrm{l}$ of 2 propanol. The grids were allowed to dry overnight at room temperature. Images of the selected regions were taken using the built-in high resolution $(7768 \times 7768)$ lens-coupled AMT XR41-B 8-megapixel camera where a minimum of about 100 Ag-NPs were considered. The particle size analysis and distribution uniformity were processed by using the capture JENNIE-X viewer software.

\section{The Experimental Animals}

Male New Zealand white rabbits, Oryctolagus cuniculus, with an average body weight of 2.1 $\pm 0.1 \mathrm{~kg}$ were used as an animal model for the current study. Rabbits were obtained from the Military Animal Farm (Cairo, Egypt). The rabbits were acclimatized seven days prior to the initiation of the experiments, in accordance with the international guideline principles for the care and use of laboratory animals (NRC, 2011). They were housed in steel cages at a temperature of $21^{\circ} \pm 2^{\circ} \mathrm{C}$, relative humidity of $40 \%$ to $50 \%$, and cyclic daylight of $12 \mathrm{~h} / \mathrm{day}$. Rabbits were fed a commercial diet with free access to water throughout all the experiments. 
Careful daily observations indicated that animals were healthy and free of diseases and pathogens throughout the duration if the experiments.

\section{The Experimental Design}

The design was arranged as acute and sub-acute exposure terms. Both terms include exposure and recovery levels. In general, the suspensions of Ag-NPs were applied topically (1ml) as a single dose $(2.0 \%)$ for acute exposure term and every other day $(0.05 \%)$ in the sub-acute term. The dosage range was based on a previous study in which the dermal toxic dose of that substance was estimated (Koraniet al., 2011).

A G-Power analysis was run to determine the best fit animal size, a total number of fifteen rabbits were used for assessing the effects of Ag-NPs in the acute exposure course. Rabbits were randomly divided into three equal groups $(n=5)$. The $1^{\text {st }}$ group served as control while the $2^{\text {nd }}$ group represented the single exposure followed by a 4-day period before assessments were made, and the $3^{\text {rd }}$ group was used for the evaluation of recovery (7days from the end of last exposure). The sub-acute exposure term was designed to evaluate the effect of Ag-NPs in two different exposure periods (EP; 7 and 14 days). The suitable number of animals was estimated by theG-Power analysis to be thirty rabbits. These rabbits were allocated into three groups ( $\mathrm{n}=10), \mathrm{IV}, \mathrm{V}$ and VI which represented the control, the exposure, and the recovery groups, respectively. Five animals from each group were used to evaluate the 7 days of subacute exposure while the other five were employed for assessment of the 14 days exposure period (Table 1).

Table 1: The full constructed design of experimentation.

\begin{tabular}{|c|c|c|c|c|c|c|c|c|c|}
\hline Terms of Exposure & \multicolumn{3}{|c|}{ Acute } & \multicolumn{6}{|c|}{ Sub-acute } \\
\hline Group number & I & II & II & \multicolumn{2}{|c|}{ IV } & \multicolumn{2}{|c|}{ V } & \multicolumn{2}{|c|}{ VI } \\
\hline Deionized H2O & $1 \mathrm{ml}$ & $\begin{array}{ll}--- \\
---\end{array}$ & $\begin{array}{ll}--- \\
---\end{array}$ & $1 \mathrm{ml}$ & $1 \mathrm{ml}$ & $\begin{array}{l}--- \\
--\end{array}$ & $\begin{array}{ll}--- \\
---\end{array}$ & $\begin{array}{ll}--- \\
--\end{array}$ & $\begin{array}{ll}--- \\
---\end{array}$ \\
\hline Ag-NPs $(0.5 \%)$ & ---- & ---- & ---- & ---- & ---- & $1 \mathrm{ml}$ & $1 \mathrm{ml}$ & $1 \mathrm{ml}$ & $1 \mathrm{ml}$ \\
\hline Ag-NPs $(2.0 \%)$ & ---- & $1 \mathrm{ml}$ & $1 \mathrm{ml}$ & $\begin{array}{l}--- \\
--\end{array}$ & $\begin{array}{ll}---- \\
---\end{array}$ & ---- & ---- & $\begin{array}{ll}---- \\
---1\end{array}$ & $\begin{array}{c}--- \\
---\end{array}$ \\
\hline Sample Size (n) & 5 & 5 & 5 & 5 & 5 & 5 & 5 & 5 & 5 \\
\hline Total sample size $(\mathrm{N})$ & \multicolumn{3}{|c|}{15} & \multicolumn{6}{|c|}{30} \\
\hline Number of exposures & \multicolumn{3}{|c|}{ Single } & \multicolumn{6}{|c|}{ Every other day } \\
\hline Exposure sampling time & $\begin{array}{c}4 \\
\text { days }\end{array}$ & $\begin{array}{c}4 \\
\text { days }\end{array}$ & ---- & $\begin{array}{c}7 \\
\text { days } \\
\end{array}$ & $\begin{array}{c}14 \\
\text { days }\end{array}$ & $\begin{array}{c}7 \\
\text { days } \\
\end{array}$ & $\begin{array}{c}14 \\
\text { days }\end{array}$ & ---- & ---- \\
\hline $\begin{array}{l}\text { Recovery sampling time } \\
\text { After end of exposure }\end{array}$ & ---- & - & $\begin{array}{c}7 \\
\text { days } \\
\end{array}$ & - & ---- & ---- & ---- & $\begin{array}{c}7 \\
\text { days } \\
\end{array}$ & $\begin{array}{c}7 \\
\text { days }\end{array}$ \\
\hline
\end{tabular}

\section{Animals Preparation and Sampling}

The dorsal backs of rabbits were clipped using electric clipper supplied with $0.22 \mathrm{~mm}$ finishing clipper blade to remove the hair without damaging the skin. An area of 6x6 cm was marked with a water-based FDA approved dye marker where the suspensions of the test material were applied. At the end of each experimental period of acute and sub-acute terms, 5 $\mathrm{ml}$ of blood werecollected from the ear lobe vein in a heparinized tube on ice. The plasma was prepared by centrifugation at $3000 \mathrm{rpm}$ for $10 \mathrm{~min}$. The plasma was stored deep frozen at 
$-20^{\circ} \mathrm{C}$ until further analysis. Afterwards, rabbits were sacrificed and the tissue samples from skin, liver, kidneys, and spleen were quickly excised. One gram of the organ tissue was separately stored frozen at $-80^{\circ} \mathrm{C}$ pending preparation for measuring the concentration of $\mathrm{Ag}+$ ions.

One gram of the skin from each rabbit was homogenized with $9 \mathrm{ml}$ phosphate buffer $(0.1$ $\mathrm{mol} / \mathrm{L}, \mathrm{PH} 7.4)$ in ice. Homogenates were centrifuged at $2500 \mathrm{rpm}$ for $10 \mathrm{~min}$ and the supernatant was collected and stored for assaying total proteins and lipid parameters. Another gram of tissue was homogenized in $8 \mathrm{ml}$ cold $50 \mathrm{mM}$ potassium phosphate-containing $1 \mathrm{mM}$ EDTA using the "POLYTRON PT-3100D" tissue homogenizer. Samples were centrifuged at $4000 \mathrm{rpm}$ for $15 \mathrm{~min}$ at $4^{\circ} \mathrm{C}$, the supernatant was collected, divided into aliquots, and kept frozen at $-80^{\circ} \mathrm{C}$ till assaying the oxidative stress biomarkers.

\section{Bioaccumulation of Silver Ions}

The concentrations of Ag ions in different tissues were estimated with the aid of an Agilent 7700 series Inductively Coupled Plasma Mass Spectrometer (ICP-MS) integrated with an auto-sampler (Agilent Technologies, Germany), according to the method described by Bergin et al. (2016). All analyses were operated at an RF power of $1500 \mathrm{~W}$ with a reflected power $\leq 1$ $\mathrm{W}$, carrier gas flow of $1.1 \mathrm{~L} / \mathrm{min}$, and a detection limit of $0.001 \mathrm{ng}$. The calibration was done using an external standard (Agilent calibration standard No: 8500-6940).

One gram of tissue or one $\mathrm{ml}$ of plasma was pre-digested for 5 hours with $5 \mathrm{ml} \mathrm{HNO}_{3}$ at room temperature. Samples were then digested with $1 \mathrm{ml} \mathrm{H}_{2} \mathrm{O}_{2}$ in an Ethos Easy microwave system (Milestone, Italy) with the following digestion parameters: power, 1200W (100\%); ramp time, $15 \mathrm{~min}$; temperature, $200^{\circ} \mathrm{C}$; hold time, $15 \mathrm{~min}$; and cooling time, $15 \mathrm{~min}$. Immediately after digestion, $5 \mathrm{ml}$ of hydrochloric acid wereadded to promote the formation of soluble silver complexes and prevent the precipitation of insoluble Ag salts. Finally, after diluting with $10 \mathrm{ml}$ of Milli-Q water and filtering through a Millipore membrane $(0.45 \mathrm{~m})$, each prepared sample was ready for measurement. The concentration of $\mathrm{Ag}$ ions in tissues was expressed as ng/g dry wt. and in plasma as $\mathrm{ng} / \mathrm{ml}$.

\section{Measurements of Total Protein and LipidParameters}

Total protein content in the skin was determined according to the Biuret reaction based on the method described by Walker (1994). Measurements were done using a colorimetric assay kit (Elabscience Bio Inc, USA, E-BC-K165) following the manufacturer's instructions, and the concentration was expressed as g/g wt. Total cholesterol was assayed based on the cholesterol oxidase phenol 4-amino-antipyrine peroxidase (CHOD-PAP) method as described by Allain et al. (1974) using a commercially available kit provided by Elabscience Bio Inc, USA, (EBC-K109). In brief, the cholesterol esters were hydrolysed to cholesterol by cholesterol esterase and then oxidized by cholesterol oxidase to yield 4-cholestenone and $\mathrm{H}_{2} \mathrm{O}_{2}$. The latter reacted with 4-aminoamylpyridine and phenol to form a red quinone compound of benzoquinone imine phenizone. The colour depth measured at $510 \mathrm{~nm}$, was directly proportional to the cholesterol content in the sample and wascalculated and expressed as $\mathrm{mmol} / \mathrm{g} \mathrm{wt}$.

The concentration of high-density lipoprotein cholesterol (HDL-Chol) was determined according to the method described by Moshides (1987), using (Elabscience Bio Inc, USA, EBC-K222) assay kit. The assaying principle was based on the ability of HDL-Chol to interact 
with cholesterol esterase and cholesterol oxidase surfactant to yield $\mathrm{H}_{2} \mathrm{O}_{2}$ and cholest-4-ene3-one. $\mathrm{H}_{2} \mathrm{O}_{2}$ was then catalyzed by oxidase in the presence of 4-aminoantipyrine and phenol to form a red quinone dye. The measured colour intensity at $546 \mathrm{~nm}$ was proportional to the HDL-Chol content in the sample. The concentration was then calculated and expressed as $\mathrm{mmol} / \mathrm{g}$.

The measurement of low-density lipoprotein cholesterol (LDL-Chol) was mainly based on two steps enzymatic assay (Elabscience Bio Inc, USA, E-BC-K206), according to the method described by Sugiuchiet al. (1998). In the first step, lipoproteins other than LDL in the test sample were decomposed by the action of cholesterol esterase with the aid of ascorbic oxidase. The reaction produced $\mathrm{H}_{2} \mathrm{O}_{2}$ and cholestenone particulates that only contained LDLChol. In the second step, N-Ethyl-N-(2-hydroxy-3-sulfo-propyl)-3-methylaniline sodium salt was added to the reaction to dissociate the LDL particles. The release of cholesterol was further catalysed by cholesterol esterase and cholesterol oxidase to yield $\mathrm{H}_{2} \mathrm{O}_{2}$ that formed a red quinone compound in the presence of peroxidase and 4-aminoantipyrine. The colour depth, which was directly proportional to the LDL-Chol content in the sample, was measured at $546 \mathrm{~nm}$. The concentration was then calculated and expressed as $\mathrm{mmol} / \mathrm{g}$.

The triglycerides (TG) measurement was based on their tendency for conversion into free fatty acids and glycerol. The glycerol was then oxidized by the action of phosphate oxidase to generate $\mathrm{H}_{2} \mathrm{O}_{2}$ which in turn reacted with peroxidase to form red quinone in the presence of para-chlorophenol as an indicator (McGowan et al., 1983). The colour depth of the generated quinones measured at $510 \mathrm{~nm}$ was directly proportional to the triglycerides content $(\mathrm{mmol} / \mathrm{g})$. A commercial kit (Elabscience Bio Inc, USA, catalogue number E-BC-K261) was used in this determination.

\section{Antioxidant Enzymes and Oxidative Stress Biomarkers}

The activities of glutathione-s-transferase (GST), glutathione reductase (GR) and glutathione peroxidase (GPx) were measured using colourimetric assay kits supplied by Bio-diagnostic, Giza, Egypt (GR 2519, GR 2523 and GP 2524) according to the methods described by Habiget al. (1974), Goldberg and Spooner (1983) and Paglia and Valentine (1967), respectively.

The measurement of GST activity wasbased primarily on the conjugation of reduced glutathione with 1-chloro-2,4-dinitrobenzene (CDNB). The conjugation was accompanied by an increase in absorbance at $340 \mathrm{~nm}$. This increase was directly proportional to the GST activity in the sample. The assaying principle of GR activity wasderived from the ability of GR to catalyze the reduction of glutathione (GSSG) in the presence of NADPH, which was then oxidized to NADP+ with a noticeable decrease in absorbance at $340 \mathrm{~nm}$. The determination of the GPx activity was dependant on the oxidation-reduction cycle of glutathione in the presence of NADPH. The oxidation of NADPH was accompanied by a decrease in absorbance at $340 \mathrm{~nm}$ which was directly proportional to the amount of GPx in the sample. The activities of these antioxidant enzymes were calculated and expressed as $\mathrm{U} / \mathrm{g}$ tissue.

The activity of superoxide dismutase (SOD) was determined using a commercially available colourimetric kit (Bio-diagnostic, SD 2521). The assaying relied on the ability of the SOD enzyme to inhibit the phenazine methosulphate-mediated reduction of nitroblue tetrazolium 
dye (Nishikimiet al., 1972). This reduction was followed by an increase in absorbance measured at $560 \mathrm{~nm}$. The catalase (CAT) activity was determined according to the method described by Aebi (1984) using (Bio-diagnostic, CA 2517) assay kit. The measurement principle wasbased on the reduction of a known quantity of $\mathrm{H}_{2} \mathrm{O}_{2}$ by the action of CAT. In the presence of horseradish peroxidase, the remaining $\mathrm{H}_{2} \mathrm{O}_{2}$ reacted with 3,5-dichloro-2hydroxybenzenesulfonic acid and 4-aminophenazoneto yield a coloured dye. The measured colour intensity at $510 \mathrm{~nm}$ was inversely proportional to the amount of CAT in the sample, and the activity was calculated and expressed as $\mathrm{U} / \mathrm{g}$ tissue.

The GSH level was assayed according to the method of Beutleret al. (1963), using Biodiagnostic (GR2511) kit. The method was based on the reduction of 5,5 dithiobis, 2nitrobenzoic acid (DTNB) with glutathione (GSH) to produce a yellow compound. This reduction was directly proportional to GSH content in the sample and its absorbance was measured at $405 \mathrm{~nm}$. The concentration was then calculated and expressed as $\mathrm{mg} / \mathrm{g}$ tissue.

Lipid peroxidation was determined by measuring the concentration of malondialdehyde (MDA) in the skin samples using a colourimetric assay kit (Bio-diagnostic, MD 2529). The method depended on the ability of MDA to react with thiobarbituric acid (TBA) in an acidic medium to form a reactive pink product at $95^{\circ} \mathrm{C}$ (Ohkawaet al., 1979). The absorbance of the resultant pink product measured at $534 \mathrm{~nm}$, was directly proportional to the MDA content in the sample and was expressed as $\mathrm{nmol} / \mathrm{g}$ tissue.

In addition, the concentration of hydrogen peroxide was measured base on its reaction with 3,5-dichloro-2-hydroxy benzene sulfonic acid and 4-amino-phenazone, in the presence of peroxidase enzyme, to form a quinone dye (Bibhutiet al., 1968). The reaction was accompanied by an increase in absorbance at $510 \mathrm{~nm}$ which was proportional to the $\mathrm{H}_{2} \mathrm{O}_{2}$ concentration $(\mathrm{mM} / \mathrm{g})$ in the sample. A commercial kit (HP 25) supplied by Bio-diagnostic, Giza, Egypt, was used for this assay.

\section{Statistical Analysis}

G-power analysis was used for the estimation of thetotal number of animals $(\mathrm{N})$ and the number of animals within groups (n). The data were initially checked for normality by onesample Shapiro-Wilk test where, the null hypothesis was accepted and the calculated data were considered normally distributed when $\mathrm{P} \geq 0.05$ (Shapiro and Wilk, 1965).

In order to test the effect of different exposure levels of Ag-NPs on the examined parameters, One-way analysis of variances (ANOVA) was performed. On the other hand, Two-way ANOVA was used to determine the interactions between the exposure level and type of tissues at different exposure periods. Duncan's post hoc test was carried out for normally distributed samples with homogeneous variances, whereas Tukey HSD and Games-Howell tests were used for the heterogeneous sets. Data were expressed as mean \pm standard error of the mean (SEM), mean values were considered statistically significant at $\mathrm{P}<0.05$. All analyses were performed using the Statistical Package for the Social Sciences (SPSS) software for Windows, version 26.0 (IBM Corp. USA). 


\section{RESULTS}

\section{Characterization of Silver Nanoparticles}

TEM and SEM imaging displayed that, Ag-NPs content in both forms of non-sonicated powder or ultrasonicated aqueous suspension were homogeneously distributed with no sign of any aggregations. The examined nanoparticles were nearly spherical in shape with a smooth and clear morphological surface. In addition, the average particle size distribution of the singlet NPs was in the range of $14 \mathrm{~nm}$ (Figure 1).

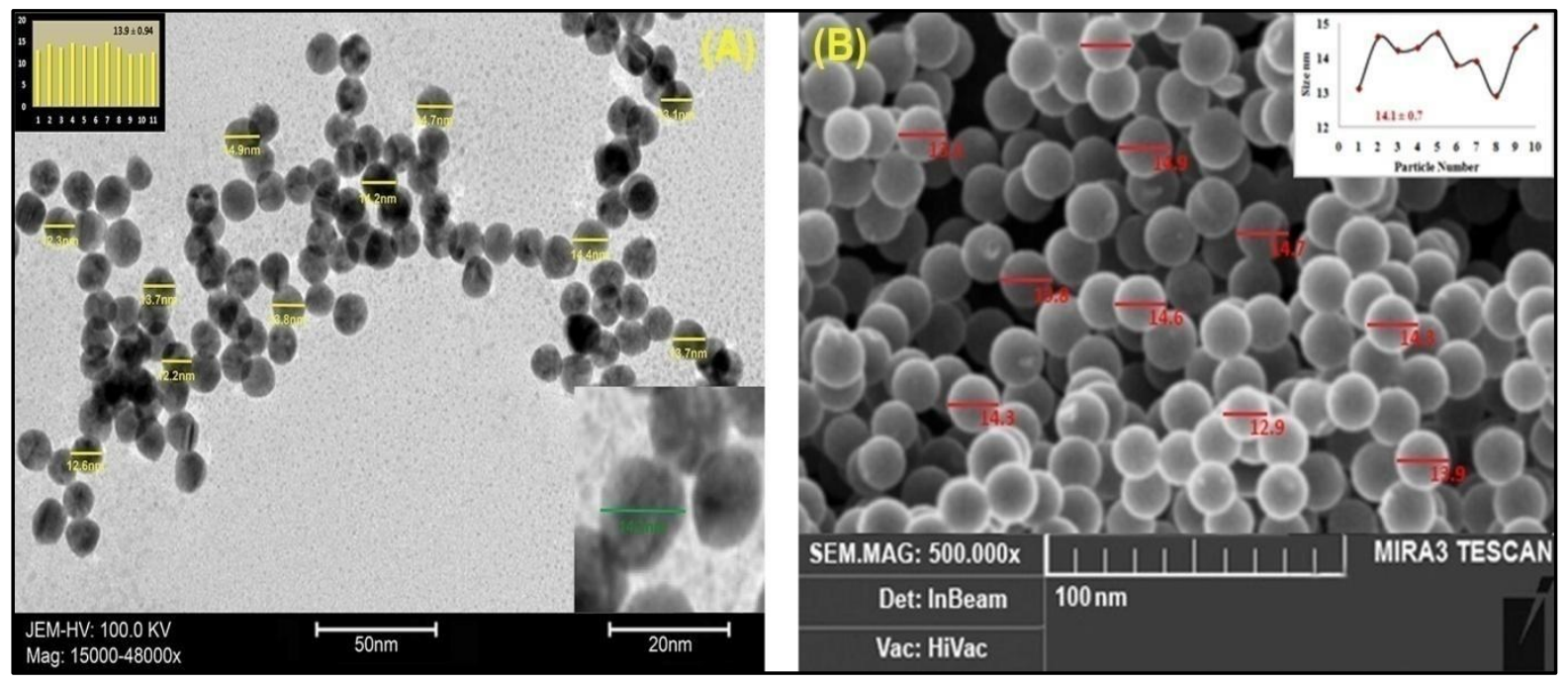

Figure 1: Electron micrographs showing the morphology and particle size distribution of the experimental silver nanoparticles. (A) TEM of the ultrasonicated Ag-NPs solution, while (B) represents the SEM of non-sonicated powder.

The presence of silver (Ag) as the main element in the examined Ag-NPs samples was highly established through the EDX analysis. On the other hand, the appearance of very few residuals of Carbon (C) elements might be reasonably explained as a result of the substrate over which they were held on the grids to perform the characterization (Figure 2). 


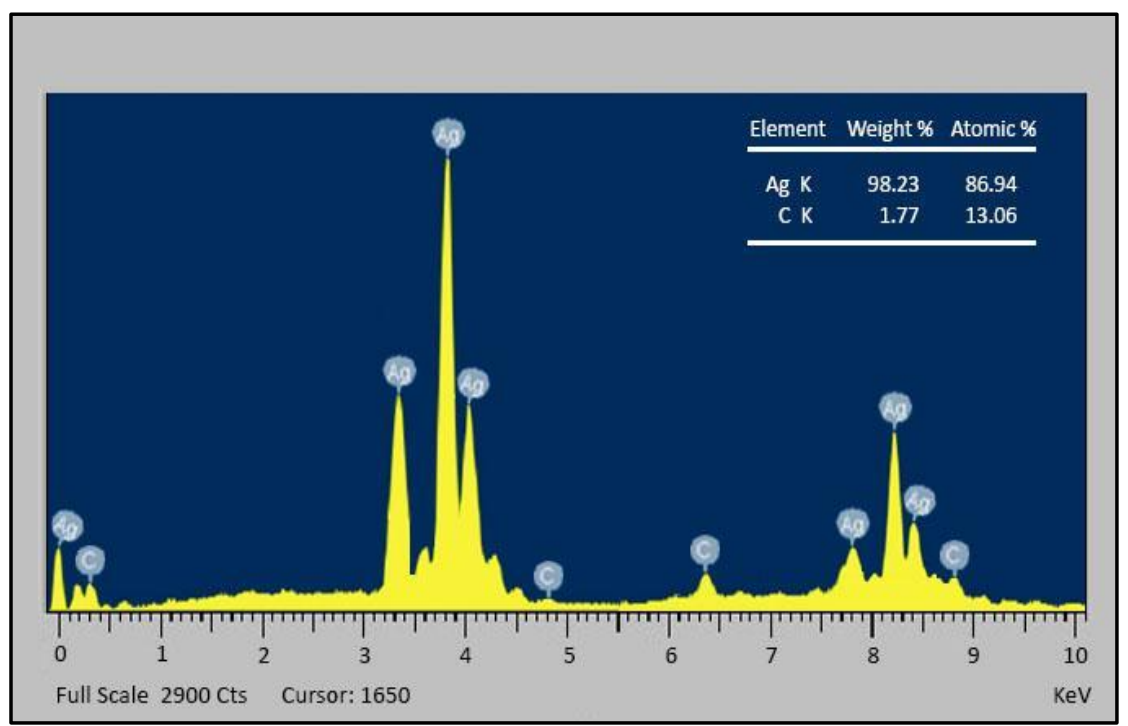

Figure 2: The EDX spectrum of Ag-NPs showing the elemental composition.

\section{The Bioaccumulation of Silver Ions}

In the acute term of the experiment, the two-way ANOVA revealed that the exposure levels (0.0 and $2.0 \%$ ), type of tissues (skin, liver, kidneys, spleen, and plasma) and their interaction caused a highly significant effect on the accumulation of $\mathrm{Ag}+$ ions after 4 days of exposure to Ag-NPs. No silver ions were detected in all the studied tissues of control rabbits (group I) whereas, the post-hoc ANOVA of the multiple comparisons displayed that the Ag+ ions accumulated in all tissuesingroup II weresignificantly greater than their levels in the corresponding tissues ingroups I and III. The spleen accumulated the highest concentration of silver which significantly was higher than that in the liver followed by skin, kidney, and plasma. In addition, the concentration of Ag residues in all tissues decreased after recovery (Table 2).

In the sub-acute experiments, the topically applied dose of $0.5 \%$ Ag-NPs caused highly significant differences in the concentration of silver in all tissues of male rabbits at the different levels of both exposure periods (EP: 7 and 14 days). The control rabbits (group IV) didn't show any accumulation of Ag ions in all the studied tissues. In contrast, the Ag ions accumulated in all tissues of the exposed rabbits (group V) were significantly greater than their levels in the corresponding tissues of normal (groups IV) and recovery (group VI) at both experimental periods. In group $\mathrm{V}$, the spleen accumulated the highest concentration of silver which was significantly higher than the mean concentration in the liver followed by skin, kidney, and plasma at both exposure periods. Moreover, the skin of the recovery rabbits (group VI) showed insignificant differences in the concentration of Ag when compared with that of control (group IV) at the 7-dayexposure period, while the circulatory concentration of Ag was down-regulated to the normal level at both exposure periods, after recovery (Table 2). 
Table 2: The concentration of accumulated silver ions in the skin, liver, kidneys, spleen (ng/g dry wt.), and plasma (ng/ml) of rabbits, following acute and sub-acute exposure to silver nanoparticles. Data are represented as a mean \pm SEM.

\begin{tabular}{|l|c|c|c|c|}
\hline \multirow{2}{*}{ Tissues } & \multicolumn{4}{|c|}{ The acute exposure term } \\
\cline { 2 - 5 } & Group I & Group II & Group III & $\%$ ( \\
\hline Skin & 0.0 & $391.1 \pm 0.9^{\mathbf{A}}$ & $041.6 \pm 0.1^{\mathbf{A B}}$ & $-89.4 \%$ \\
\hline Liver & 0.0 & $785.6 \pm 0.5^{\mathbf{A}}$ & $275.9 \pm 1.1^{\mathbf{A B}}$ & $-64.9 \%$ \\
\hline Kidney & 0.0 & $292.4 \pm 0.8^{\mathbf{A}}$ & $141.6 \pm 0.4^{\mathbf{A B}}$ & $-51.6 \%$ \\
\hline Spleen & 0.0 & $793.4 \pm 0.4^{\mathbf{A}}$ & $368.5 \pm 0.6^{\mathbf{A B}}$ & $-53.6 \%$ \\
\hline Plasma & 0.0 & $141.5 \pm 0.4^{\mathbf{A}}$ & $024.7 \pm 0.2^{\mathbf{A B}}$ & $-82.5 \%$ \\
\hline
\end{tabular}

\begin{tabular}{|l|c|c|c|c|}
\hline \multirow{2}{*}{ Tissues } & \multicolumn{4}{|c|}{ The sub-acute exposure term } \\
\cline { 2 - 5 } & Group IV & Group V & Group VI & $\% \mathbf{~}$ \\
\hline Skin & & & & \\
7 days & 0.0 & $86.87 \pm 0.3^{\mathbf{A}}$ & $0.00 \pm 0.0^{\mathbf{B}}$ & $-100 \%$ \\
14 days & 0.0 & $244.43 \pm 0.8^{\mathbf{A}}$ & $12.56 \pm 0.3^{\mathbf{A B}}$ & $-94.9 \%$ \\
\hline Liver & & & & \\
7 days & 0.0 & $160.24 \pm 0.5^{\mathbf{A}}$ & $20.15 \pm 0.3^{\mathbf{A B}}$ & $-87.4 \%$ \\
14 days & 0.0 & $482.38 \pm 0.5^{\mathbf{A}}$ & $117.34 \pm 0.4^{\mathbf{A B}}$ & $-75.7 \%$ \\
\hline Kidney & & & & $-81.6 \%$ \\
7 days & 0.0 & $60.87 \pm 0.2^{\mathbf{A}}$ & $11.23 \pm 0.2^{\mathbf{A B}}$ & $-53.7 \%$ \\
14 days & 0.0 & $179.29 \pm 0.4^{\mathbf{A}}$ & $82.95 \pm 0.3^{\mathbf{A B}}$ & \\
\hline Spleen & & & & \\
7 days & 0.0 & $184.69 \pm 0.5^{\mathbf{A}}$ & $33.91 \pm 0.2^{\mathbf{A B}}$ & $-81.6 \%$ \\
14 days & 0.0 & $581.96 \pm 0.5^{\mathbf{A}}$ & $182.80 \pm 0.4^{\mathbf{A B}}$ & $-68.6 \%$ \\
\hline Plasma & & & & \\
7 days & 0.0 & $10.31 \pm 0.1^{\mathbf{A}}$ & $0.00 \pm 0.0^{\mathbf{B}}$ & $-100 \%$ \\
14 days & 0.0 & $34.89 \pm 0.4^{\mathbf{A}}$ & $0.00 \pm 0.0^{\mathbf{B}}$ & $-100 \%$ \\
\hline
\end{tabular}

(1): Percentage of changes after recovery in relation to the exposure group of rabbits.

(A) and (B): In the same row, indicated a significant difference $(\mathrm{P}<0.05)$ in comparison with the control and exposure groups respectively, as demonstrated by ANOVA at $\alpha=0.05$.

\section{Total Protein and Lipid Parameters}

The statistical analysis confirmed that the concentrationsof total protein in the skin of rabbits in group II and III were significantly lower than that of the control rabbits(group IV), following the acute exposure to Ag-NPs (2.0\%, 4 days). On the other hand, the effects of accumulated $\mathrm{Ag}+$ in the concentrations of total protein in the skin of sub-acute experimental rabbits $(0.5 \%, 7$ and 14 days) weretime-dependent. No significant effect was recorded after 7 days of exposure, while a significant decrease was detected in the skin of the exposure (group V) and recovery (group VI) when compared with the controls (groups IV), at the 14-day experimental period. In addition, ANOVA with the subsequent multiple comparison tests 
affirmed that the administered doses of Ag-NPs in both theacute and sub-acute exposure terms had no significant effects on all lipid parameters under investigation. The concentrations of total Chol, HDL-Chol, LDL-Chol and triglycerides were insignificantly changed at the different assessment levels and exposure periods (Table 3).

Table 3: The concentration of total proteins $(\mathrm{mg} / \mathrm{g}$. wt) and the lipid parameters (mmol/g. wt) in the skin of rabbits, following acute and sub-acute exposure to Ag-NPs. Data are represented as a mean \pm SEM.

\begin{tabular}{|l|c|c|c|c|c|}
\hline \multirow{2}{*}{ Parameters } & \multicolumn{5}{|c|}{ The acute exposure term } \\
\cline { 2 - 6 } & Group I & Group II & \% & Group III & $\% \mathbf{~}$ \\
\hline T-Proteins & $4.19 \pm 0.04$ & $3.95 \pm 0.06^{\mathbf{A}}$ & $-5.7 \%$ & $4.08 \pm 0.06^{\mathbf{A B}}$ & $+3.3 \%$ \\
\hline Total-Chol & $0.81 \pm 0.03$ & $0.83 \pm 0.03$ & $0.0 \%$ & $0.82 \pm 0.02$ & $0.0 \%$ \\
\hline HDL-Chol & $0.22 \pm 0.01$ & $0.24 \pm 0.02$ & $0.0 \%$ & $0.23 \pm 0.01$ & $0.0 \%$ \\
\hline LDL-Chol & $0.56 \pm 0.03$ & $0.57 \pm 0.02$ & $0.0 \%$ & $0.56 \pm 0.02$ & $0.0 \%$ \\
\hline TGs & $0.33 \pm 0.01$ & $0.35 \pm 0.02$ & $0.0 \%$ & $0.34 \pm 0.01$ & $0.0 \%$ \\
\hline
\end{tabular}

\begin{tabular}{|l|c|c|c|c|c|}
\hline \multirow{2}{*}{ Parameters } & \multicolumn{5}{|c|}{ The sub-acute exposure term } \\
\cline { 2 - 6 } & Group IV & Group V & \% & Group VI & $\%$ Q \\
\hline T-Proteins & & & & & \\
7 days & $4.23 \pm 0.03$ & $4.22 \pm 0.04$ & $0.0 \%$ & $4.23 \pm 0.05$ & $0.0 \%$ \\
14 days & $4.22 \pm 0.03$ & $4.06 \pm 0.02 \mathrm{~A}$ & $-3.8 \%$ & $4.11 \pm 0.07 \mathrm{AB}$ & $+1.2 \%$ \\
\hline Total-Chol & & & & & \\
7 days & $0.82 \pm 0.02$ & $0.81 \pm 0.01$ & $0.0 \%$ & $0.80 \pm 0.04$ & $0.0 \%$ \\
14 days & $0.83 \pm 0.02$ & $0.82 \pm 0.03$ & $0.0 \%$ & $0.83 \pm 0.02$ & $0.0 \%$ \\
\hline HDL-Chol & & & & & \\
7 days & $0.23 \pm 0.01$ & $0.24 \pm 0.01$ & $0.0 \%$ & $0.24 \pm 0.01$ & $0.0 \%$ \\
14 days & $0.23 \pm 0.02$ & $0.23 \pm 0.01$ & $0.0 \%$ & $0.24 \pm 0.02$ & $0.0 \%$ \\
\hline LDL-Chol & & & & & \\
7 days & $0.58 \pm 0.03$ & $0.57 \pm 0.03$ & $0.0 \%$ & $0.57 \pm 0.02$ & $0.0 \%$ \\
14 days & $0.57 \pm 0.05$ & $0.56 \pm 0.02$ & $0.0 \%$ & $0.56 \pm 0.03$ & $0.0 \%$ \\
\hline TGs & & & & & \\
7 days & $0.34 \pm 0.02$ & $0.36 \pm 0.02$ & $0.0 \%$ & $0.36 \pm 0.02$ & $0.0 \%$ \\
14 days & $0.35 \pm 0.03$ & $0.36 \pm 0.03$ & $0.0 \%$ & $0.37 \pm 0.02$ & $0.0 \%$ \\
\hline
\end{tabular}

1): Percentage of changes after exposure in relation to the control group of rabbits.

2: Percentage of changes after recovery in relation to the exposure group of rabbits.

(A) and (B): In the same row, indicated a significant difference $(\mathrm{P}<0.05)$ in comparison with the control and exposure groups respectively, as demonstrated by ANOVA at $\alpha=0.05$. 


\section{The Antioxidant Enzymes and Oxidative Stress Biomarkers}

In the present work, the antioxidant results demonstrated a remarkable increase in the enzymatic activity of GST, GR and GPx in the skin of male rabbits, after the dermal exposure to Ag-NPs in both acute and sub-acute experimental terms. In contrast, the skin showed a significantly decreased level of GSH during these exposure terms. The effect of Ag-NPs on the examined antioxidants during the acute exposure period was significantly higher than that of the sub-acute experimental term. In addition, the disturbed activity of GST, GR, GPx as well as GSH level in the skin of exposure rabbits was more profound than that of the recovery level when compared with the normal values of the corresponding controls respectively, during both exposure terms (Tables 4 and 5).

In addition, statistically significant decrease in the activities of SOD and CAT were displayed alongside a highly increased level of $\mathrm{H}_{2} \mathrm{O}_{2}$ as well as in MDA in the skin of exposed (group II) and recovery (group III) rabbits when compared with those of controls (group I), after 4 days of acute exposure to $2.0 \%$ Ag-NPs. In addition, rabbits of sub-acute exposure to $0.5 \%$ Ag-NPs showed a similar pattern of the effect regarding these parameters throughout the different experimental periods. The effect of Ag-NPs during sub-acute exposure seemed to be time dependant where the activities of SOD and CAT were dropped gradually below the control levels during the 7 days of exposure and reached a minimum level at the 14th day of experiments (Tables 4 and 5).

A noticeable regulated level of SOD, CAT, and $\mathrm{H} 2 \mathrm{O} 2$ were found in the skin of recovery rabbits (group VI) in relation to those of exposure level (group V). They regained normal levels of the corresponding control (group IV) during the 7 days period while their levels were still significantly different after 14 days of exposure. In general, the significantly increased $\mathrm{H}_{2} \mathrm{O}_{2}$ level probably signified that the first line antioxidant defence system including SOD and CAT was not efficient enough to prevent the initiated oxidative stress in the skin following exposure to Ag-NPs. Moreover, the increased levels of MDA as a a reliable biomarker affirmed the peroxidation of fatty acids following exposure to Ag-NPs (Tables 4 and 5).

Table 4: The levelsof GSH (mg/g), MDA (nmol/g), and $\mathrm{H}_{2} \mathrm{O}_{2}(\mathrm{mM} / \mathrm{g})$ in the skin of male rabbits, following acute and sub-acute exposure to Ag-NPs. Data are represented as a mean \pm SEM.

\begin{tabular}{|l|c|c|c|c|c|}
\hline \multirow{2}{*}{ Parameters } & \multicolumn{5}{|c|}{ The acute exposure term } \\
\cline { 2 - 6 } & Group I & Group II & \% $\mathbf{0}$ & Group III & \% 2 \\
\hline GSH & $56.7 \pm 0.59$ & $33.1 \pm 0.53^{\mathbf{A}}$ & $-42 \%$ & $38.2 \pm 0.73^{\mathbf{A B}}$ & $+16 \%$ \\
\hline $\mathrm{MDA}$ & $24.4 \pm 0.14$ & $35.7 \pm 0.19^{\mathbf{A}}$ & $+46 \%$ & $31.2 \pm 0.11^{\mathrm{AB}}$ & $-13 \%$ \\
\hline $\mathrm{H}_{2} \mathrm{O}_{2}$ & $1.40 \pm 0.02$ & $1.92 \pm 0.03^{\mathbf{A}}$ & $+39 \%$ & $1.76 \pm 0.02^{\mathrm{AB}}$ & $-9 \%$ \\
\hline
\end{tabular}




\begin{tabular}{|l|c|c|c|c|c|}
\hline \multirow{2}{*}{ Parameters } & \multicolumn{5}{|c|}{ The sub-acute exposure term } \\
\cline { 2 - 6 } & Group IV & Group V & $\%$ 1 & Group VI & $\%$ 2 \\
\hline GSH & & & & & \\
7 days & $56.5 \pm 0.59$ & $51.4 \pm 0.58^{\mathbf{A}}$ & $-9 \%$ & $56.6 \pm 0.67^{\mathbf{~ B}}$ & $+10 \%$ \\
14 days & $56.7 \pm 0.62$ & $38.6 \pm 0.64^{\mathbf{A}}$ & $-32 \%$ & $44.9 \pm 0.35^{\mathbf{A B}}$ & $+17 \%$ \\
\hline $\mathrm{MDA}$ & & & & & \\
7 days & $24.3 \pm 0.08$ & $25.8 \pm 0.07^{\mathbf{A}}$ & $+6 \%$ & $24.4 \pm 0.14^{\mathbf{B}}$ & $-5 \%$ \\
14 days & $24.6 \pm 0.09$ & $29.7 \pm 0.13^{\mathbf{A}}$ & $+22 \%$ & $26.4 \pm 0.04^{\mathbf{A B}}$ & $-11 \%$ \\
\hline $\mathrm{H}_{2} \mathrm{O}_{2}$ & & & & & \\
7 days & $1.38 \pm 0.02$ & $1.46 \pm 0.02^{\mathbf{A}}$ & $+6 \%$ & $1.38 \pm 0.02^{\mathbf{B}}$ & $-6 \%$ \\
14 days & $1.39 \pm 0.01$ & $1.81 \pm 0.01^{\mathbf{A}}$ & $+33 \%$ & $1.74 \pm 0.02^{\mathbf{A B}}$ & $-7 \%$ \\
\hline
\end{tabular}

(1) Percentage of changes after exposure in relation to the control group of rabbits.

2: Percentage of changes after recovery in relation to the exposure group of rabbits.

(A) and (B): In the same row, indicated a significant difference $(\mathrm{P}<0.05)$ in comparison with the control and exposure groups respectively, as demonstrated by ANOVA at $\alpha=0.05$.

Table 5: The activities of the antioxidant enzymes GST, GR, GPx, SOD and CAT expressed as (U/g) in the skin of male rabbits, following acute and sub-acute exposure to Ag-NPs. Data are represented as a mean \pm SEM.

\begin{tabular}{|c|c|c|c|c|c|}
\hline \multirow{2}{*}{ Parameters } & \multicolumn{5}{|c|}{ The acute exposure term } \\
\hline & Group I & Group II & $\% 1$ & Group III & $\% 2$ \\
\hline GST & $17.2 \pm 0.02$ & $21.8 \pm 0.004^{\mathrm{A}}$ & $+27 \%$ & $19.1 \pm 0.007^{\mathbf{A B}}$ & $-12 \%$ \\
\hline GR & $165.3 \pm 0.5$ & $195.1 \pm 0.49^{\mathrm{A}}$ & $+18 \%$ & $182.5 \pm 0.53^{\mathrm{AB}}$ & $-7 \%$ \\
\hline GPx & $551.6 \pm 2.6$ & $727.9 \pm 1.86^{\mathbf{A}}$ & $+32 \%$ & $649.3 \pm 3.52^{\mathrm{AB}}$ & $-11 \%$ \\
\hline SOD & $\begin{array}{c}153.3 \pm 0 \\
9\end{array}$ & $121.5 \pm 0.20^{\mathbf{A}}$ & $-21 \%$ & $137.1 \pm 0.03^{\mathrm{AB}}$ & $+13 \%$ \\
\hline CAT & $0.74 \pm 0.02$ & $0.39 \pm 0.002^{\mathrm{A}}$ & $-47 \%$ & $0.46 \pm 0.002^{\mathrm{AB}}$ & $+18 \%$ \\
\hline
\end{tabular}

\begin{tabular}{|l|c|c|c|c|c|}
\hline \multirow{2}{*}{ Parameters } & \multicolumn{5}{|c|}{ The sub-acute exposure term } \\
\cline { 2 - 6 } & Group IV & Group V & $\%$ ( & Group VI & $\%$ 2 \\
\hline GST & & & & & \\
7 days & $17.1 \pm 0.05$ & $17.3 \pm 0.02^{\mathbf{A}}$ & $0.0 \%$ & $17.2 \pm 0.06^{\mathbf{B}}$ & $0.0 \%$ \\
14 days & $17.2 \pm 0.04$ & $20.7 \pm 0.02^{\mathbf{A}}$ & $+18 \%$ & $18.6 \pm 0.01^{\mathbf{A B}}$ & $-9 \%$ \\
\hline GR & & & & & \\
7 days & $165.6 \pm 0.6$ & $171.5 \pm 0.47^{\mathbf{A}}$ & $+4 \%$ & $165.7 \pm 0.58^{\mathbf{B}}$ & $-3 \%$ \\
14 days & $165.5 \pm 0.4$ & $189.9 \pm 0.61^{\mathbf{A}}$ & $+15 \%$ & $174.8 \pm 0.58^{\mathbf{A B}}$ & $-8 \%$ \\
\hline
\end{tabular}


African Journal of Biology and Medical Research

ISSN: $2689-534 \mathrm{X}$

Volume 4, Issue 4, 2021 (pp. 34-52)

www.abjournals.org

\begin{tabular}{|l|c|c|c|c|c|}
\hline GPx & & & & & \\
7 days & $553.3 \pm 3.4$ & $603.06 \pm 1.53^{\mathbf{A}}$ & $+9 \%$ & $554.6 \pm 3.11^{\mathbf{B}}$ & $-8 \%$ \\
14 days & $552.1 \pm 1.3$ & $684.76 \pm 1.59^{\mathbf{A}}$ & $+24 \%$ & $628.9 \pm 1.53^{\mathbf{A B}}$ & $-8 \%$ \\
\hline SOD & & & & & \\
7 days & $153.2 \pm 0.1$ & $141.11 \pm 0.15^{\mathbf{A}}$ & $-8 \%$ & $153.07 \pm 0.16^{\mathbf{B}}$ & $+9 \%$ \\
14 days & $153.3 \pm 0.1$ & $129.13 \pm 0.08^{\mathbf{A}}$ & $-16 \%$ & $143.88 \pm 0.17^{\mathbf{A B}}$ & $+11 \%$ \\
\hline CAT & & & & & \\
7 days & $0.74 \pm 0.01$ & $0.74 \pm 0.003$ & $0.0 \%$ & $0.74 \pm 0.003$ & $0.0 \%$ \\
14 days & $0.74 \pm 0.03$ & $0.51 \pm 0.003^{\mathbf{A}}$ & $-31 \%$ & $0.62 \pm 0.002^{\mathbf{A B}}$ & $+22 \%$ \\
\hline
\end{tabular}

(1) Percentage of changes after exposure in relation to the control group of rabbits.

2: Percentage of changes after recovery in relation to the exposure group of rabbits.

(A) and (B): In the same row, indicated a significant difference $(\mathrm{P}<0.05)$ in comparison with the control and exposure groups respectively, as demonstrated by ANOVA $\alpha=0.05$.

\section{DISCUSSION}

In the current study, the ICP-MS technique has been successfully used for mapping the distribution and elimination of silver ion in different tissues of male rabbits after dermal exposure to Ag-NPs. Our results confirmed that the interaction of exposure levels with type of tissues caused a highly significant effect on the accumulation of Ag+ ions. The spleen of exposed rabbits accumulated the maximum concentration of silver which was significantly higher than the mean concentration in the liver followed by skin, kidney, and plasma when compared with the control and recovery rabbits at both experimental terms. In consequence, we may suggest that Ag-NPs were able to penetrate the skin layers and predominantly circulate with the blood until translocation and deposition into different tissues.

These results are in accordance with the fact that Ag-NPs have the ability to pass through the healthy skin via follicular and sebaceous gland pathways before ultimately being distributed to the main organs where they accumulate (Kraelinget al., 2018). In addition, recent studies have demonstrated the ability of Ag-NPs to enter the bloodstream. They first come in contact with the vascular endothelial cells and easily translocate to the spleen and liver which become the base of their activity as well as their elimination (Poznańskiet al., 2021). Both tissues represent a major part of the reticulo-endothelial system which has the facility for engulfment of accumulated Ag+ through the resident phagocytes such as Kupffer cells in the liver and B cells in the spleen (Colinoet al., 2020).

The current data also displayed that the concentration of Ag+ in the blood rapidly declined followed by other tissues in the following sequence blood >skin > kidney> liver > spleen after the recovery period, when compared with those of the exposure rabbits but,these levels were still higher than the levels of the corresponding controls. This outcome signified the ability of rabbits to eliminate $\mathrm{Ag}+$ from the different tissues through a relatively concise recovery time. The acquired tendency of Ag-NPs to aggregate in the presence of electrolytes might give a good explanation for these resuts. In particular, the body fluids of mammals contain large 
amounts of chloride and sulfide ions which are able to interact with $\mathrm{Ag}+$ forming bulky insoluble salts, thus facilitatingtheir elimination (Zhang et al., 2013).

On the other hand, the effectof Ag-NPs on the concentration of totalproteins and lipid profile were investigated to explore the possible toxicity impact on the main metabolic constituents. In the present study, a highly significant decrease in the concentration of total protein was displayed in the skin of male rabbits at the exposure and recovery levels of both acute (2.0\%, 4 days) and sub-acute $(0.5 \%, 14$ days) exposure terms to Ag-NPs, respectively. In contrast, no obvious changes in the level of total proteins were observed following the sub-acute exposure for 7 days. Moreover, no significant changes in the concentrations of total cholesterol, HDL-Chol, LDL-Chol or in the levels of triglycerides were recorded.

The most reasonable explanation of the significantly decreased concentration of total proteins in the skin could be arising from the affinity of $\mathrm{Ag}+$ ions for several functional protein macromolecules containing thiol, sulfhydryl, phosphate, carboxyl, and amine groups, thereby changing their structure and causing their inactivation (Liu et al. 2013; Ogniket al. 2016). In support of this assumption, several researchers have suggested that NPs can cause linkage of tissue proteins by the formation of protein corona, which may lead to unfolding, and altered protein functions (Rampado et al., 2020). Previous studies reported Ag-NPs linked protein corona by incubating fetal bovine serum with $20 \mathrm{~nm}$ stabilized silver for 24 hours and found that albumin, keratins, and other serum proteins interacted with Ag-NPs forming corona (Shannahan et al., 2013).

The antioxidant cellular machinery has naturally developed for maintaining redox homeostasis and controlling the pro-oxidant balance under normal physiological conditions (Schieber and Chandel, 2014). This mechanism contains enzymatic antioxidants such as SOD, CAT, GST, GPx, GR and non-enzymatic antioxidants including ascorbic acid, lipoic acid, vitamins, ubiquinol, and GSH (Sies, 2018). In the present work, the antioxidant results demonstrated a remarkable increase in the enzymatic activity of GST, GR and GPx as well as the levels of MDA and $\mathrm{H}_{2} \mathrm{O}_{2}$ in the skin, after the dermal exposure to Ag-NPs in both acute and sub-acute experimental terms. In contrast, the skin showed a significant decrease in the GSH level as well as the activities of SOD and CAT during these exposure terms.

The effect of Ag-NPs on the examined antioxidants during the acute exposure period was significantly higher than that on the sub-acute experimental term. In addition, the disturbed activities of GST, GR, GPx, SOD and CAT as well as GSH, MDA and $\mathrm{H}_{2} \mathrm{O}_{2}$ levels in the skin of the exposure rabbits were more profound than that of the recovery level when compared with the corresponding controls,during both exposure terms. Our results also confirmed that the levels of these antioxidants were partially regained after the recovery time. Hence, we hypothesize that the effects were not permanent and could be overcome by maintaining the normal antioxidant levels after a sufficient recovery period.

It is known that GST is a phase II selenium-independent antioxidant. it is generally activated in response to the increased levels of ROS and is very efficient in neutralizing the free radicals and xenobiotics by catalyzing their conjugation with GSH as an electron donor (Cooper and Hanigan, 2018). Consequently, GST could be indirectly involved in the consumption of GSH during its action which may explain, in part, the decrease in GSH. Previous studies indicated that Ag-NPs induced GSH depletion, either by inhibiting its 
synthesizing enzymes or increasing its consumption during the neutralization of ROS by GPx and GST enzymes (Mosaet al., 2019; Yousef et al., 2019).

The GPxcatalyzes reactionsthat consume GSH as a cofactor which in turn oxidized it to GSSG (Ighodaro and Akinloye, 2018). Accordingly, GSH depletion seems to be ascribed to its excessive oxidation during its action as a substrate for GPx. Thus, the recorded significant increase in GR activity during the current work could be explained as an essential reaction that is consistent with the increased demand for recycling the oxidized GSSG, thereby recovering the reduced GSH level in consequence to keep the normal redox homeostasis (Kelly et al., 2019).

In addition, the dissolution of Ag-NPs is well documented to be accelerated inside cells to generate free $\mathrm{Ag}+$ ions, which in turn oxidized by $\mathrm{H}_{2} \mathrm{O}_{2}$ through a Fenton-like reaction (Polo et al., 2017). The oxidation process leads to the production of excessive ROS, including the superoxide $(\mathrm{O} 2 \bullet-)$ and hydroxyl $(\mathrm{OH} \bullet)$ radicals as well as singlet $\mathrm{O} 2$ (Jones et al., 2011). This fact could provide a good explanation to our results where the decreased activity of SOD might be attributed to its rapid consumption or fully saturation during the process of converting $\mathrm{O} 2$ - to $\mathrm{H} 2 \mathrm{O} 2$. Whereas, the increased generation of $\mathrm{H} 2 \mathrm{O} 2$ may have led to the inhibition of CAT activity. Generally, it is currently accepted that the alteration of the enzyme activity might be due to either regulation of genes or to direct surface interaction of the enzymes with Ag-NPs (Akteret al., 2018; Wei et al., 2020).

The increased level of MDA observed herein, may be correlated to the increased production of ROS after exposure to Ag-NPs or as an indicator of disturbed activity or efficiency of the antioxidant defence system. In all cases, the elevated MDA level is an essential sign of lipid peroxidation and oxidative stress that have been associated with several diseases (Bergin et al., 2021). Regarding this issue, Harikiran and Yellu (2017) reported greater induction of oxidative stress in rats following the intra-tracheal installation of Ag-NPs, which was associated with ROS accumulation and lipid peroxidation as indicated by the increased levels of MDA and GSH as well as reduced activities of SOD and CAT. MDA is highly reactive in forming covalent bonds with several proteins in the cytoplasm and nucleus thereby, modifying their structures and functions (Hardianyet al., 2020). This may contribute to explaining the reduced concentration of total proteins observed herein via conjugation with the excessive MDA.

\section{CONCLUSION}

The present study succeeded to elaborate the potential hazards and the biological effects of Ag-NPs when applied on the skin. The toxicity of Ag-NPs as well as their capability to pass the skin layers and spread to other vital tissues seemed to depend on their concentration and exposure time. Ag-NPs exert their toxic effects in a sequential manner that is initiated by the intercellular accumulation of Ag+ with the subsequent increased generation of ROS over the antioxidant defence capacity which led to severe cellular damage by initiating oxidative stress and affecting macromolecules such as proteins. 


\section{REFERENCES}

Aebi H. (1984). Catalase in vitro. Methods in enzymology, 105, 121-126.

Akter, M., Sikder, M. T., Rahman, M. M., Ullah, A., Hossain, K., Banik, S., Hosokawa, T., Saito, T., \&Kurasaki, M. (2017). A systematic review on silver nanoparticles-induced cytotoxicity: Physicochemical properties and perspectives. Journal of advanced research, 9, 1-16.

Allain, C. C., Poon, L. S., Chan, C. S., Richmond, W., \& Fu, P. C. (1974). Enzymatic determination of total serum cholesterol. Clinical chemistry,20(4), 470-475.

Antony, J. J., Sivalingam, P., \& Chen, B. (2015). Toxicological effects of silver nanoparticles. Environmental toxicology and pharmacology, 40(3), 729-732.

Bayda, S., Adeel, M., Tuccinardi, T., Cordani, M., \&Rizzolio, F. (2019). The History of Nanoscience and Nanotechnology: From Chemical-Physical Applications to Nanomedicine. Molecules (Basel, Switzerland), 25(1), 112-137.

Bergin, I. L., Wilding, L. A., Morishita, M., Walacavage, K., Ault, A. P., Axson, J. L., Stark, D. I., Hashway, S. A., Capracotta, S. S., Leroueil, P. R., Maynard, A. D., \&Philbert, M. A. (2016). Effects of particle size and coating on toxicologic parameters, foecal elimination kinetics and tissue distribution of acutely ingested silver nanoparticles in a mouse model. Nanotoxicology, 10(3), 352-360.

Bergin, P., Leggett, A., Cardwell, C. R., Woodside, J. V., Thakkinstian, A., Maxwell, A. P., \& McKay, G. J. (2021). The effects of vitamin E supplementation on malondialdehyde as a biomarker of oxidative stress in haemodialysis patients: a systematic review and meta-analysis. BMC nephrology, 22(1), 126-148.

Beutler, E., Duron, O., \& Kelly, M. (1963). Improved method for the determination of blood glutathione. The Journal of laboratory and clinical medicine, 61, 882-888.

Beyene, D., Werkneh, A., Bezabh, A., \&Ambaye, G. (2017): Synthesis paradigm and applications of silver nanoparticles (AgNPs), A review. Sustainable Materials and Technologies, 13, 18-23.

Bibhuti, R. DasGupta, B., \& Daniel, A. (1968). Quantitative Spectrophotometric determination of hydrogen peroxide with p-dimethylaminobenzaldehyde. Analytical Chemistry Journal, 40 (13): 2060-2062.

Čapek, J., \&Roušar, T. (2021). Detection of Oxidative Stress Induced by Nanomaterials in Cells-The Roles of Reactive Oxygen Species and Glutathione. Molecules (Basel, Switzerland), 26(16), 4710-4732.

Colino, C. I., Lanao, J. M., \& Gutierrez-Millan, C. (2020). Targeting of Hepatic Macrophages by Therapeutic Nanoparticles. Frontiers in immunology, 11, 218-234.

Cooper, A.L., \& Hanigan, M.H. (2018): Metabolism of Glutathione S-Conjugates: Multiple Pathways. Comprehensive Toxicology, 363-406.

Gherasim, O., Grumezescu, A. M., Grumezescu, V., Iordache, F., Vasile, B. S., \&Holban, A. M. (2020). Bioactive Surfaces of Polylactide and Silver Nanoparticles for the Prevention of Microbial Contamination. Materials (Basel, Switzerland), 13(3), 768-782.

Goldberg, D.M., and Spooner, R.J. (1983). Methods of. Enzymatic Analysis. (Bergmeyen, H.V. Ed.). 3rd ed. 3: 258-265.

Gopisetty, M. K., Kovács, D., Igaz, N., Rónavári, A., Bélteky, P., Rázga, Z., Venglovecz, V., Csoboz, B., Boros, I. M., Kónya, Z., \&Kiricsi, M. (2019). Endoplasmic reticulum stress: a major player in size-dependent inhibition of P-glycoprotein by silver nanoparticles in multidrug-resistant breast cancer cells. Journal of nanobiotechnology, 17(1), 9-21. 
Habig, W. H., Pabst, M. J., \&Jakoby, W. B. (1974). Glutathione S-transferases. The first enzymatic step in mercapturic acid formation. The Journal of biological chemistry, 249(22), 7130-7139.

Hardiany, N., Sucitra, S., \& Paramita, R. (2020). Profile of malondialdehyde (MDA) and catalase specific activity in plasma of elderly woman. Health Science Journal of Indonesia, 10(2), 132-136.

Harikiran, L., \&Yellu, N. (2017). Evaluation of oxidative stress induction in rats following exposure to silver nanorods. Toxicology mechanisms and methods, 27(4), 272-278.

Jones, A. M., Garg, S., He, D., Pham, A. N., \& Waite, T. D. (2011). Superoxide-mediated formation and charging of silver nanoparticles. Environmental science \& technology, 45(4), 1428-1434.

Kelly, R. A., Leedale, J., Calleja, D., Enoch, S. J., Harrell, A., Chadwick, A. E., \& Webb, S. (2019). Modelling changes in glutathione homeostasis as a function of quinone redox metabolism. Scientific reports, 9(1), 6333-6344.

Korani, M., Rezayat, S. M., Gilani, K., ArbabiBidgoli, S., \&Adeli, S. (2011). Acute and subchronic dermal toxicity of nanosilver in guinea pigs. International journal of nanomedicine, 6, 855-862.

Kraeling, M., Topping, V. D., Keltner, Z. M., Belgrave, K. R., Bailey, K. D., Gao, X., \&Yourick, J. J. (2018). In vitro percutaneous penetration of silver nanoparticles in pig and human skin. Regulatory toxicology and pharmacology: RTP, 95, 314-322.

Larsson, S., Jansson, M., \&Boholm, A. (2019). Expert stakeholders' perception of nanotechnology: risk, benefit, knowledge, and regulation. Nanoparticles Research Journal, 21, 57-66.

Liu, H., Yang, D., Yang, H., Zhang, H., Zhang, W., Fang, Y., Lin, Z., Tian, L., Lin, B., Yan, J., \& Xi, Z. (2013). Comparative study of respiratory tract immune toxicity induced by three sterilisation nanoparticles: silver, zinc oxide and titanium dioxide. Journal of hazardous materials, 249, 478-486.

McGowan, M. W., Artiss, J. D., Strandbergh, D. R., \& Zak, B. (1983). A peroxidase-coupled method for the colourimetric determination of serum triglycerides. Clinical chemistry, 29(3), 538-542.

Mosa, I., Youssef, M., Shalaby, T., \&Mosa, O. (2019). The protective role of tannic acid against possible Hepato-nephrotoxicity induced by Silver Nanoparticles on male rats. SANAMED, 14(2): 131-145.

Moshides J. S. (1987). Kinetic enzymatic method for automated determination of HDL cholesterol in plasma. Journal of clinical chemistry and clinical biochemistry, 25(9), 583-587.

Mulvaney P. (2015). Nanoscience vs nanotechnology--defining the field. ACS nano, 9(3), 2215-2217.

Nishikimi, M., Appaji, N., \& Yagi, K. (1972). The occurrence of superoxide anion in the reaction of reduced phenazine methosulfate and molecular oxygen. Biochemical and biophysical research communications, 46(2), 849-854.

NRC, National Research Council. (2011). Guide for the Care and Use of Laboratory Animals, 8th ed. National Academies Press.

Ognik, K., Sembratowicz, I., Cholewinska, E., Wlazlo, L., Nowakowicz-Debek, B., Szlazak, R., \&Tutaj, K. (2016): The effect of chemically-synthesized silver nanoparticles on performance and the histology and microbiological profile of the jejunum in chickens. Annals of Animal Science, 16, 1-12. 
Ohkawa, H., Ohishi, N., \& Yagi, K. (1979). Assay for lipid peroxides in animal tissues by thiobarbituric acid reaction. Analytical Biochemistry,95(2), 351-358.

Paglia, D. E., \& Valentine, W. N. (1967). Studies on the quantitative and qualitative characterization of erythrocyte glutathione peroxidase. The Journal of laboratory and clinical medicine, 70(1), 158-169.

Polo, A., Lopez-Peñalver, J. J., Rivera-Utrilla, J., Von Gunten, U., \& Sánchez-Polo, M. (2017). Halide removal from waters by silver nanoparticles and hydrogen peroxide. The Science of the total environment, 608, 649-657.

Poznański, J., Sołdacki, D., Czarkowska-Pączek, B., Bonna, A., Kornasiewicz, O., Krawczyk, M., Bal, W., \&Pączek, L. (2021). Cirrhotic Liver of Liver Transplant Recipients Accumulate Silver and Co-Accumulate Copper. International journal of molecular sciences, 22(4), 1782-1791.

Rampado, R., Crotti, S., Caliceti, P., Pucciarelli, S., \& Agostini, M. (2020). Recent Advances in Understanding the Protein Corona of Nanoparticles and in the Formulation of "Stealthy". Frontiers in bioengineering and biotechnology, 8(166), 2324-2343.

Sajid, M., \&Płotka, W. J. (2020). Nanoparticles: Synthesis, characteristics, and applications in analytical and other sciences. Microchemical Journal, 154, 104623-39.

Sapkota, K., Narayanan, K.B., \& Han, S.S. (2017). Environmentally sustainable synthesis of catalytically active silver nanoparticles and their cytotoxic effect on human keratinocytes. Journal of Cluster Science, 28,1605-1616.

Schieber, M., \& Chandel, N. S. (2014). ROS function in redox signalling and oxidative stress. Current biology: CB, 24(10), R453-R462.

Shannahan, J. H., Lai, X., Ke, P. C., Podila, R., Brown, J. M., \&Witzmann, F. A. (2013). Silver nanoparticle protein corona composition in cell culture media. PloS one, 8(9), e74001.

Shapiro, S. S., \& Wilk, M. B. (1965). An Analysis of Variance Test for Normality (Complete Samples). Biometrika, 52(3/4), 591-611.

Sies, H. (2018). On the history of oxidative stress: concept and some aspects of current development. Current Opinion in Toxicology, 7, 122-126.

Staroń, A., Długosz, O., Pulit-Prociak, J., \& Banach, M. (2020). Analysis of the Exposure of Organisms to the Action of Nanomaterials. Materials, 13(2), 349-368.

Sugiuchi, H., Irie, T., Uji, Y., Ueno, T., Chaen, T., Uekama, K., \& Okabe, H. (1998). Homogeneous assay for measuring low-density lipoprotein cholesterol in serum with triblock copolymer and alpha-cyclodextrin sulfate. Clinical chemistry, 44(3), 522-531.

Walker J. M. (1994). The bicinchoninic acid (BCA) assay for protein quantitation. Methods in molecular biology (Clifton, N.J.), 32, 5-8.

Wei, L., Isabelle, W., \& Vera, I. S. (2020). Interaction of silver nanoparticles with antioxidant enzymes. Environmental Science Journal: Nano, 7, 1507- 1517.

Yousef, M. I., Abuzreda, A. A., \& Kamel, M. A. (2019). Cardiotoxicity and lung toxicity in male rats induced by long-term exposure to iron oxide and silver nanoparticles. Experimental and therapeutic medicine, 18(6), 4329-4339.

Zhang, S., Du, C., Wang, Z., Han, X., Zhang, K., \& Liu, L. (2013). Reduced cytotoxicity of silver ions to mammalian cells at high concentration due to the formation of silver chloride. Toxicology in vitro: an international journal published in association with BIBRA, 27(2), 739-744. 